\title{
КОММУНИКАЦИЯ РАБОТНИКОВ КАК СРЕДСТВО ПРЕОДОЛЕНИЯ ПРОЦЕССА НЕОПРЕДЕЛЕННОСТИ УЧЕТНОЙ СРЕДЫ ПРИ УЧЕТЕ ОСНОВНЫХ СРЕДСТВ
}

\section{(c) 2021 Листопад Екатерина Евгеньевна}

кандидат экономических наук, доцент Департамента аудита и корпоративной отчетности Финансовый университет при Правительстве Российской Федерации, Россия, Москва

E-mail: eelistopad@fa.ru

В статье основное внимание уделяется пониманию условной природы бухгалтерского учета, автор пытается предложить такую коммуникацию сотрудников, которая поможет преодолеть процесс неопределенности учетной среды. Неопределенность рассматривается на примере учета ликвидационной стоимости и ликвидационного обязательства по основным средствам, а также проблемам определения приведенной стоимости оценочного обязательства. Автор пытается предложить решение такому вопросу, как бухгалтерская (финансовая) отчетность передает информацию о ставке дисконтирования и как влияет на достоверность информации условия неопределенности?

Ключевые слова: неопределенность учетной среды, учет оценочных обязательств, оценка ликвидационной стоимости, дисконтирование, коммуникация сотрудников.

В настоящее время бухгалтерский учет является единственной формой обработки информации, встречающихся во всех организациях, любой организационно-правовой формы собственности и любого вида деятельности. Однако, бухгалтерский учет принципиально противоположен неопределенности, поэтому жесткая зависимость от бухгалтерского учета является несовместимой с ситуациями высокой неопределенности, т.е. сама суть бухгалтерского учета ей противоречит. Считаем, что методы и функции бухгалтерского учета (в частности, его контрольная функция) являются полезными и незаменимыми в условиях неопределенности. А также в современных условиях необходимости принятия решений по отражению зачастую условных активов и обязательств, осуществление переоценки и дисконтирования их величин, проверки на обесценение активов, бухгалтерский учет как экономическая категория переходит в среду неопределенности, где субъективизм оценок можно нивелировать профессиональным суждением финансовых работников.

В соответствии с новыми требованиями учета при поступлении основных средств [2,5], организации обязаны определять расходы по демонтажу, а также ликвидационную стоимость каждого инвентарного объекта. Первая величина ложится в основу оценочного обязательства, которое отражается в отчетности по приведенной (дисконтированной) стоимости. Поэтому, с течением времени эта оценка должна быть скорректирована на ставку дисконтирования. Неопределенность учетной среды заключается в выборе ставки, которую должен применить бухгалтер для расчета приведенной стоимости ликвидационного обязательства. В последствии неопределенность учетной среды усиливается проблемами отражения в учете результатов дисконтирования, а также формирования информации в отчетности применяемой ставке дисконтирования. И наконец, как сформировать достоверную отчетность в условиях неопределенности. Все эти вопросы требуют дальнейшей проработки.

Вторую величину организации обязаны исключить при расчете суммы начисленной амортизации. Таким образом, организации будут иметь некую величину, которая в длительной перспективе будет являться активом, с течением времени стоимость которого также может быть подвержена изменению. Однако, сначала необходимо обосновать существование нового актива в организации, а именно: соответствует ли он требованиям, предъявляемым к активам. Так, согласно Концепции развития бухгалтерского учета и отчетности активом признаются хозяйственные средства, которые организация контролирует в результате событий прошлых периодов и которые в будущем способны приносить экономические выгоды в порядке, характерном для признания актива, а именно:

- использован для производства продукции, работ, услуг; 
- обменен на другой актив;

- распределен между собственниками организации;

- направлен на погашение обязательств [1].

По этим двум критериям получается, что в бухгалтерском учете правомерность признания ликвидационной стоимости активом обоснована. Далее необходимо ответить на вопрос оценки этого актива, а также его отражения на счетах бухгалтерского учета в случае изменения его величины.

Вопросам оценки в бухгалтерском учете посвящено немало статей и монографий. Однако, исключить субъективизм при определении ликвидационной стоимости основных средств невозможно. Все понимают, что практически все объекты основных средств после окончания срока полезного использования, даже в случае их морального устаревания, можно продать с выгодой для организации. Однако, предсказать спрос на большинство внеоборотных активов через несколько лет затруднительно. Поэтому любая оценка ликвидационной стоимости будет иметь условный характер, т.е. бухгалтеру необходимо действовать в условиях неопределенности. Считаем, что вопросы оценки ликвидационной стоимости должны решаться на уровне комиссии, созданной в организации из сотрудников соответствующих технических структур, также необходимо включить в комиссию сотрудников финансового отдела (департамента). Считаем, что справедливость такой оценки будет иметь наименьший субъективизм.

В дальнейшем согласно ФСБУ 21/10 «Изменения оценочных значений» ликвидационная стоимость может быть изменена, такие изменения учитываются как изменения оценочных значений, а именно: перспективно с отражением возникшей разницы по счетам учета прочих доходов и расходов [4]. Минфин ошибочно полагает, что перспективное отражение результатов изменения оценки ликвидационной стоимости позволит сформировать достоверную отчетность. Как минимум требование сопоставимости данных будет нарушено. Поэтому необходимо дальнейшее реформирование бухгалтерского учета и отчетности в нашей стране. Что касается счета прочих доходов и расходов, то применение его для изменения суммы накопленной амортизации, по нашему мнению, приведет к вуалированию данных в отчетности, а именно: в отчете о финансовых результатах будет отражаться ре- зультат, который никакого отношения к прочей деятельности не имеет. Считаем, что отражение изменения оценочного значения в части амортизации основных средств необходимо отражать ретроспективно с отражением возникшей разницы дополнительной или сторнированной записью. Тогда полученные результаты в бухгалтерском балансе и отчете о финансовых результатах, по нашему мнению, будут отражать достоверную информацию о стоимости объектов основных средств.

Что касается вопросов дисконтирования ликвидационного обязательства, то в ФСБУ 8/10 «Оценочные обязательства, условные обязательства и условные активы» приводится требование к установлению ставки дисконтирования. Применяемая организацией ставка дисконтирования:

a) должна отражать существующие на финансовом рынке условия, а также риски, специфичные для обязательства, лежащего в основе признаваемого оценочного обязательства [3].

Таким образом, за основу ставки дисконтирования необходимо взять существующие условия, действующие на финансовом рынке. В настоящий момент в РФ установлена ключевая ставка Банка России (анг. The key rate of the Bank of Russia), которую многие авторы предлагают использовать в условиях неопределенности учетной среды в качестве основы для проведения операций по дисконтированию обязательств ожидаемых потерь в будущем. Действительно, данная ставка оказывает влияние на все продукты банковского сектора, однако не является полной. Так, на ключевую ставку влияют более, чем на половину ставки по корпоративным кредитам, в то время как изменение процентной ставки по депозитам оказывает влияние на изменение ключевой ставки не более, чем на $40 \%$. Но банковские продукты являются не единственным моментом, оказывающим влияние на ключевую ставку. Основное влияние оказывает время, а именно: все изменения процентных ставок занимают время, запаздывание составляет от двух-трёх месяцев до одного года. Ну и наконец, последнее, различная сила влияния банковского продукта в зависимости от его срока:

- депозитный рынок: краткосрочные ставки реагируют на изменение ключевой ставки быстрее и сильнее, чем долгосрочные;

- кредитный рынок носит противоположный характер. 
Таким образом, считаем, что неполнота и асимметричность процентного канала ключевой ставки может являться свидетельством невозможности применения его при расчете приведенной стоимости внеоборотных активов.

Вопрос о том, какую ставку применить для дисконтирования, полностью находится в компетенции менеджмента компании: слишком много разного рода допущений может быть сделано при выборе ставки. Большие трудности ожидают компанию при обосновании выбранной ставки дисконтирования внешним пользователям, например аудиторам. Обычно аудиторы обосновывают свои ставки как best practice. Зачастую финансовые менеджеры компании соглашаются с предложенными аудиторами ставками, а не пытаются доказать свою точку зрения. При этом практики применения ставки дисконтирования для определения приведенной стоимости активов в нашей стране нет. Некоторые эксперты рекомендуют применять ставку дисконтирования, равную средневзвешенной стоимости капитала, т.е. значению WACC (Weighted average cost of capital) аналогичной компании, акции которой котируются на бирже.

Стоимость финансирования (ставка дисконтирования) - это средневзвешенная стоимость привлечения финансирования/капитала из разных источников. Простейшая формула для расчета средневзвешенной стоимости капитала может быть записана в таком виде:

\section{$\mathrm{WACC}=\mathrm{W}_{\text {д }} \mathrm{R}_{\text {д }}+\mathrm{W}_{\mathrm{a}} \mathrm{R}_{\mathrm{a}}$}

где $\mathrm{W}_{\text {д и }} \mathrm{W}_{\mathrm{a}}$ - это целевые веса для долгового (д) и собственного (принадлежащего акционерам) (а) капитала $(\mathrm{W}$ от слова weight $=\mathrm{Bec})$. Понятно, что $\mathrm{W}_{\text {д }}+\mathrm{W}_{\mathrm{a}}=1.0$;

a $\mathrm{R}_{\text {д }}$ и $\mathrm{R}_{\mathrm{a}}$ - это соответствующая стоимость капитала $(\mathrm{R}$ от слова Rate $=$ ставка процента) [7].

На наш взгляд использование этого показателя неоправданно. Если менеджмент компании знает, насколько рисковый актив, то и без использования этого показателя, тем более рассчитанного для чужой компании, сможет определить ставку дисконтирования. Кроме того, у каждой компании структура капитала, а также соотношение собственных и заемных средств будут разными, поэтому величина средневзвешенной стоимости капитала другой компании вряд ли подойдет для каждого конкретного случая. Поэтому многие эксперты предлагают использовать рыночную ставку за привлечение внешнего финансирования, исходя из действующих ставок по кредитам на основании официальных данных крупнейших банков нашей страны. Приведем основные ставки, действующие по состоянию на 31.03.2021 г. (табл.1). Средневзвешенная рыночная ставка за привлечение внешнего финансирования составит 7,87\%.

Какую методику выбрать решает менеджмент компании. Выбор будет зависеть от задач развития компании, потому что процент по кредитам и займам как правило ниже стоимости капитала компании. Если у организации цель показать более высокую рыночную стоимость активов, то выбор ее будет в пользу более низкой ставки дисконтирования.

Таким образом, можно сделать вывод, что в настоящее время неопределенность учетной среды заключается не только в определении первоначальной оценки таких новых объектов учета, как ликвидационная стоимость и ликвидационные обязательства в учете основных средств, но и их дальнейшей оценки, что в конечном счете влияет на качество формирования отчетности, на ее достоверность.

Решение проблемы неопределенности учетной среды многие ученые видят во внедрении стандартизации для выбора метода определения ставки дисконтирования [8,9]. Организация стандартизации ложится, по их мнению, в основу разработки не только учетной политики, но и регламента учета операций по дисконти-

Таблица 1. Ставки по кредитам на 31.03.2021 г.[6]

\begin{tabular}{|l|l|l|l|}
\hline \multicolumn{1}{|c|}{ № п/п } & \multicolumn{1}{|c|}{ Наименование банка } & \multicolumn{1}{c|}{ Ставка по кредитам, \% } & \multicolumn{1}{c|}{ Срок кредита } \\
\hline 1 & Сбербанк & 10,9 & От 3 лет \\
\hline 2 & ВТБ & От 6 & До 7 лет \\
\hline 3 & Газпромбанк & От 5 & До 7 лет \\
\hline 4 & Россельхозбанк & 7,7 & 540 дн. \\
\hline 5 & Тинькофф & От 12 & До 5 лет \\
\hline 6 & Райффайзен банк & 7,99 & До 5 лет \\
\hline 7 & Альфа банк & 5,5 & До 7 лет \\
\hline
\end{tabular}


рованию (так называемого «дерева» проводок). Данный регламент необходимо применять последовательно в течение всей жизни компании. По нашему мнению, бухгалтерский учет как инструмент организационного контроля существует не как набор методов, а как текущие процессы. Таким образом, можно ожидать, что стандартизация операций по дисконтированию не приведет к ожидаемым результатам, а именно: формированию достоверной отчетности, лишенной доли субъективизма. Считаем, что менеджеры, вовлеченные в такие процессы, будут играть существенную роль в их формировании, что в свою очередь скажется на качестве формируемой информации.

В настоящем исследовании предполагается, что для дальнейшего развития нашего понимания условной природы бухгалтерского учета необходимо также изучить процессы, посредством которых формальные методы бухгалтерского учета могут быть связаны с более широкой организационной деятельностью.

Опросы руководителей высшего звена, вовлеченных в процесс управления деятельностью компании, чтобы выявить роль бухгалтерского учета в компании, приводят к установлению несомненности важности составления бюджета, калькуляции затрат и финансовом контроле, однако обратную связь, преимущества и недостатки этих различных методов они будут обсуждать по-разному.

С одной стороны, бюджеты представляют как инструмент предварительного планирования деятельности, которая затем может контролироваться бухгалтерами с необходимой обратной связью (оперативным менеджерам) для обеспечения выполнения бюджета.

Другая точка зрения представляет бюджет как возможность обсуждения того, какие будущие действия могут быть уместны, и как планировать изменения, которые разворачивающиеся события сделали необходимыми. В таких организациях первостепенная роль бюджета заключается в том, чтобы направлять бизнес вперед. В отличие от отдаленного и ретроспективного контроля, подразумеваемого за соблюдением бюджетных целей, здесь роль бухгалтеров, по-видимому, предполагает заботу о будущих возможностях и результатах.

Эти две совершенно разные характеристики приводят к возможности вариации в отношениях между бухгалтерским учетом и операцион- ными процессами, что выходит на первостепенное место в связи с выполнением требования полноты бухгалтерского учета в связи с неопределенностью: в весьма определенных условиях бухгалтерия может надеяться передать относительно полные представления о событиях. Однако в крайне неопределенных ситуациях учет становится все более неполным и должен подкрепляться другими способами описания событий, чтобы представить относительно полную версию событий. Учитывая это, можно ожидать, что повышенная неопределенность должна оказывать влияние не на наличие или отсутствие бухгалтерской информации, а на ее взаимосвязь с другими видами и формами информации.

Таким образом, эмпирическое обоснование относительно условного характера бухгалтерского учета убедительно подтверждают идею о том, что бухгалтерский учет действительно играет полезную роль в условиях высокой неопределенности и что модели взаимодействия бухгалтеров, по-видимому, являются решающим сдерживающим фактором в этих отношениях.

Для того, чтобы попытаться сформулировать некоторые систематические ожидания относительно роли бухгалтерского учета в условиях неопределенности, необходимо изложить плюсы и минусы различных стратегий организации обработки информации по мере роста неопределенности. Эта структура имеет два основных преимущества. Во-первых, она прямо говорит о случайной природе как организационных процессов, так и структур. Во-вторых, путем разработки определения, основанного на информации что касается неопределенности, то эта структура позволяет нам продвигать наш анализ независимо от значительной проблемы интегрирования меры неопределенности в исследование. В рамках этой концепции неопределенность описывается как дефицит между объемом информации, которой обладает организация, и объемом информации, требуемой для данного уровня эффективности.

Когда неопределенность низка, то заранее спланированная деятельность одновременно возможна и желательна, и что в этой обстановке наиболее подходящей стратегией обработки информации были бы вертикальные системы. Когда неопределенность низка, каждая организация может быть разложена на специальные группы, которые могут сосредоточиться на кон- 
кретных аспектах деятельности, разрабатывая стандартные оперативные процедуры и тщательное понимание финансовых последствий их деятельности. Затем планы и бюджеты позволяют определить и скоординировать деятельность этих групп для достижения желаемого результата.

Впоследствии анализ бюджетных отклонений служит для обеспечения достижения заранее запланированных целей, требуя при этом минимальных постоянных усилий.

По мере развития событий иерархия необходима только для того, чтобы иметь дело с отклонениями от планов посредством отчетов об исключениях. В том случае, если потребуется внести изменения в первоначальный план, это может быть сформулировано и передано через иерархические системы. Это возможно потому, что низкая неопределенность означает, что финансовые и операционные последствия любых необходимых изменений, а также требования к их интеграции на уровне всей организации поддаются бухгалтерскому расчету и оптимизации. В значительной степени это позволяет отдельным группам свободно концентрироваться на своей собственной деятельности с координацией, встроенной в заранее запланированные действия, а также отслеживаемой и обновляемой на уровнях администрирования без существенного прерывания потока оперативной деятельности. При относительной полноте бухгалтерских репрезентаций, сопровождающейся низкой неопределенностью, бухгалтерские цифры могут говорить сами за себя, образуя виртуальную иерархию.

Однако по мере роста неопределенности уменьшается необходимая информация о том, какие действия необходимы для достижения желаемых результатов, и возможность эффективного распределения этой информации через бухгалтерскую отчетность.

Альтернативой расширению возможностей обработки информации (помимо принятия более низкого уровня производительности) является снижение требований к обработке информации путем введения слабины в качестве буфера против неопределенности. Например, занижение величины ликвидационной стоимости не означает, что компания действовала умышленно, можно сделать вывод о применения ее требования осмотрительности. А если будет занижена оценка ликвидационного обя- зательства, а также не обоснован выбор ставки дисконтирования, может привести к признанию аудиторами фальсифицированной отчетности.

Однако в конечном счете увеличение стоимости буферов, таких как основные средства, станет слишком высоким, и неопределенность подорвет преимущества предварительного планирования, поддерживаемого вертикальными системами обработки информации. В этот момент более органично требуется структура обработки информации, а именно в этот момент возникает необходимость введения разветвлений по вертикальной иерархии, позволяя субъединицам напрямую взаимодействовать.

Это, в свою очередь, позволяет организации узнать, чего требует меняющаяся ситуация и как лучше всего ее обеспечить. Представляется разумным ожидать, что внимание к финансовым последствиям таких продолжающихся изменений будет составлять значительную часть такого процесса.

По нашему мнению изменение роли бухгалтерского учета будет иметь значительные последствия для такого характера потоков бухгалтерской информации во всей организации.

В условиях определенности бухгалтерский учет поддерживает интеграцию отдельных групп внутри организации, обеспечивая эффективную работу по интеграции и коммуникации. Таким образом, бухгалтерское понимание организации может служить фундаментальной частью более общей организационной коммуникации. В частности, если бухгалтерский учет становится менее полным из-за неопределенности, то мы должны ожидать более высокого уровня вербальной коммуникации бухгалтеров, поскольку они пытаются собрать воедино свои отчеты и впоследствии сообщить (обнаружить) их смысл (последствия).

Таким образом, условный характер бухгалтерского учета - это способ интеграции бухгалтерского учета в рамках компании в более широкие организационные задачи посредством изучения моделей взаимодействия бухгалтеров. В частности, при определенных условиях работа предполагает, что подход к организации с круговым планированием приведет к высокой производительности. Последствия такого подхода с точки зрения моделей коммуникации будут заключаться в относительной раздробленности отдельных групп внутри организации.

В неопределенных условиях именная работа 
предполагает, что непрерывный подход к взаимодействию приведет к высокой производительности. Предполагается, что существенным аспектом такого подхода будет более интенсивная коммуникация между организационными группами.

Формулировать свои ожидания непредвиденных обстоятельств оценки ликвидационных обязательств возможно индивидуально в разработанных таблицах. Впоследствии после интенсивной коммуникации между созданными организационными группами возможно изменение оценок и принятие самой достоверной из них в условии неопределенности, т.е. относительная раздробленность приведет к повышению производительности в части определения субъективных оценок в условиях неопределенности бухгалтерского учета.

Что касается вопросов стандартизации процесса неопределенности, автор настаивает на том, что этот процесс не приведет к результативности, которую можно измерить качеством информации в отчетности, достоверность которой будет подтверждена аудиторами. Единственное, что можно регламентировать это создание разрозненных рабочих групп, требования к кандидатам таких групп, а также порядок и частоту их коммуникаций.

\section{Библиографический список}

1. Приказ Минфина РФ № 180 от 01.07.2004 г. «Концепция развития бухгалтерского учета и отчетности в Российской Федерации на среднесрочную перспективу»

2. Федеральный стандарт по бухгалтерскому учету 6/2020 «Основные средства», Приказ Минфина РФ № 204н от 17.09.2020 г.

3. Федеральный стандарт по бухгалтерскому учету $8 / 10$ «Оценочные обязательства, условные обязательства и условные активы», Приказ Минфина РФ № 167н от 13.12.2010 г.

4. Федеральный стандарт по бухгалтерскому учету $21 / 08$ «Изменения оценочных значений», Приказ Минфина РФ № 106н от 06.10.2008 г.

5. Федеральный стандарт по бухгалтерскому учету $26 / 2020$ «Капитальные вложения», Приказ Минфина РФ № 204н от 17.09.2020 г.

6. Потребительские кредиты 2021 ТОП 100 лучших кредитов по процентной ставке для физических лиц // www.http://banki.ru

7. Коэффициент дисконтирования дохода в розничном кредитовании, премия за кредитный риск //https:// uktankodrom.ru/stavka-diskontirovaniya/

8. Бабаев Ю.А., Друцкая М.В., Кеворкова Ж. А., Листопад Е.Е., Петров А. М. Бухгалтерский учет, анализ и аудит внешнеэкономической деятельности / учебник для студентов обучающихся по специальности 080109 «Бухгалтерский учет, анализ и аудит» / под редакцией Ю.А. Бабаева. Москва, 2010

9. Листопад Е.E. Бухгалтерский учет операций по импорту на основе риск - ориентированного подхода и его стандартизация//Экономические науки// 2020, № 5 